\title{
CAMA
}

Centre for Applied Macroeconomic Analysis

\section{The Moderating Role of Green Energy and Energy- Innovation in Environmental Kuznets: Insights from Quantile-Quantile Analysis}

\section{CAMA Working Paper 39/2020 Aprill 2020}

\section{Hammed Oluwaseyi Musibau}

Tamanian School of Business and Economics, University of Tasmania

\section{Maria Yanotti}

Tamanian School of Business and Economics, University of Tasmania

\section{Joaquin Vespignani}

Tamanian School of Business and Economics, University of Tasmania

Centre for Applied Macroeconomic Analysis, ANU

\section{Rabindra Nepal}

School of Accounting, Economics, and Finance, University of Wollongong Centre for Applied Macroeconomic Analysis, ANU

\section{Abstract}

The recent environmental challenges in Africa emanated from global warming, human activity, limited access to electricity, and over exploitation of natural resources, have contributed to the growth of carbon dioxide (CO2) emissions in the region. This paper empirically investigates the moderating role of green energy consumption and energy innovation in the environmental Kuznets' curve for the Sub-Saharan African (SSA) region using data spanning from 1980 to 2018. Our threshold model found that at least 54 per cent of population need access to energy innovation before the region could be safe from environmental degradation. We conclude that investment in green energy, energy innovation, and conservation of natural resources will help to mitigate environmental degradation in SSA in the long run. Policies should be targeted towards encouraging the consumption of green energy, and more investment in energy innovation beyond the estimated threshold will save the region from pollution and its implications. 


\section{Keywords}

Environmental Kuznets Curve, Green energy, Energy innovation, CO2 emission, SSA countries; and Quantile-Quantile regression

\section{JEL Classification}

\section{Address for correspondence:}

(E) cama.admin@anu.edu.au

ISSN 2206-0332

The Centre for Applied Macroeconomic Analysis in the Crawford School of Public Policy has been established to build strong links between professional macroeconomists. It provides a forum for quality macroeconomic research and discussion of policy issues between academia, government and the private sector.

The Crawford School of Public Policy is the Australian National University's public policy school, serving and influencing Australia, Asia and the Pacific through advanced policy research, graduate and executive education, and policy impact. 


\title{
The Moderating Role of Green Energy and Energy- Innovation in Environmental Kuznets: Insights from Quantile-Quantile Analysis
}

\author{
Hammed Oluwaseyi Musibau ${ }^{1}$, Maria Yanotti ${ }^{1}$, Joaquin Vespignani ${ }^{1,3}$, and Rabindra \\ Nepal $^{2}$ \\ ${ }^{1}$ Tamanian School of Business and Economics, University of Tasmania, Australia. \\ ${ }^{2}$ School of Accounting, Economics, and Finance, University of Wollongong, Australia. \\ ${ }^{3}$ Centre for Applied Macroeconomic Analysis, ANU
}

\begin{abstract}
The recent environmental challenges in Africa emanated from global warming, human activity, limited access to electricity, and over exploitation of natural resources, have contributed to the growth of carbon dioxide (CO2) emissions in the region. This paper empirically investigates the moderating role of green energy consumption and energy innovation in the environmental Kuznets' curve for the Sub-Saharan African (SSA) region using data spanning from 1980 to 2018. Our threshold model found that at least 54 per cent of population need access to energy innovation before the region could be safe from environmental degradation. We conclude that investment in green energy, energy innovation, and conservation of natural resources will help to mitigate environmental degradation in SSA in the long run. Policies should be targeted towards encouraging the consumption of green energy, and more investment in energy innovation beyond the estimated threshold will save the region from pollution and its implications.
\end{abstract}

Keywords: Environmental Kuznets Curve; Green energy; Energy innovation; CO2 emission; SSA countries; and Quantile-Quantile regression.

Correspondence: E-mail_mizbauhameed2010@gmail.com, +61415388734 
Most environmental turmoils of the past recent decades emanated from global warming. Undoubtedly, the contribution of economic resources such as capital, labour, natural resources, and other factor of production are largely responsible for the growth of carbon dioxide $(\mathrm{CO} 2)$ emissions, which have dramatically increased in the last decades (Bekun, Alola, \& Sarkodie, 2019). Furthermore, sustainability of humans and natural resources, has been challenged by environmental degradation, in particular $\mathrm{CO} 2$ emissions.

According to UN Climate Summit (2019), CO2 emissions growth rate is nearly $20 \%$ higher in the last five years. Meanwhile, Carbon Footprint (2018) reported an increase of around 45\% over the last 130 years. Empirical evidence shows aggravated $\mathrm{CO} 2$ levels having a direct impact on weather and climate systems, and natural disasters -- such as storms and flooding, unprecedented wildfires in the Arctic region, massive forest fires in Canada and Sweden and Australia amongt others -- have been linked to weather and global warming causing human, ecosystems and economic losses.

In the sixth Global Environment Summit held in Paris, UNEP (2019), policymakers in various countries were advised to take immediate action in addressing pressing environmental issues and to keep the global warming under control to achieve the Sustainable Development Goals. However, United Nations issued a special report advising that a global reduction of $1.5^{0} / 2^{\circ} \mathrm{C}$ was required for people and the ecosystems' equitable and sustainable society. To complement this, UN Environmental (2018) has been offering pathways to contribute to the reduction in the emissions gap surging momentum from the private sector and untapped potential from innovation and green-financing.

EIA (2015) linked CO2 emissions due to energy consumption as a main driver, accounting for almost $80 \%$ of global warming. In that case, efficiency in the energy sector is among the objectives of reducing $\mathrm{CO} 2$ emissions and moderate climate change. Many regions, including SSA, are taking a great effort in reducing $\mathrm{CO} 2$ emissions via green energy investment such as renewable energy (Bélaïd \& Youssef, 2017).

For Africa, a potential increase in energy supply is highly important for the region as over 620 million people still has no access to the electricity supply(Monyei, Adewumi, Obolo, \& Sajou, 2018; Prasad \& Samikannu, 2018). Renewable energy supply becomes an alternative power source due to a reduction in the cost of technology and its ability to ensuring energy efficiency to mitigate environmental issues. Even though Africa hasn't yet taken full advantage of its renewable energy resources, the continent has worked to increase renewable energy capacity in recent years. The shared of renewable energy generated in the African region accounts for $20 \%$ of the entire world generation (EIA, 2016).

SSA owns the largest reserves of non-renewable energy, such as coal, gas, oil and the recently discovered fuel. However, building infrastructure to exploit these huge reserves and green technological innovations may help the region, to reduce its energy absorption and CO2 emissions. The renewable energy policy network (REPN, 2015) reported that some African countries had enacted long policies on renewable investment to achieve energy goals. 
Abuse of the access to natural resources (such as oil, iron ore, gold, and bitumen) in SSA has been a significant driver of environmental degradation in the region (Yusuf, Abubakar, \& Mamman, 2020). Natural resources represent the main source of capital and means of livelihood in SSA. In particular, the oil-producing African countries are exposed to the hazards of oil extraction and refining activities, which produce negative effects on greenhouse gas emissions on the environment. The African environment and society are posed to danger as greenhouse gas emissions increase (Adzawla, Sawaneh, $\&$ Yusuf, 2019) due to a high dependency on natural resources for agricultural production and low technological advancement. United Nations, (2015a, p.13) states that SSA is the most vulnerable region in the world. Due to environmental degradation, an insignificant number of Africans have access to clean water worsening the water and sanitation challenges in the region (UNECA, 2015b).

This research aims to contribute to the existing literature by investigating the validity of the Environmental Kuznets Curve (EKC) hypothesis for Sub-Sahara Africa (SSA), alongside the mediating roles of green energy investment and information technology on the environment. While few studies have investigated the roles of green energy investment -- Dogan and Ozturk (2017), Bélaïd and Youssef (2017) -- and information technology -- Álvarez-Herránz, Balsalobre, Cantos, \& Shahbaz, 2017, previous research has not paid attention to the total effect of both factors on the EKC hypothesis. The inclusion of these two factors sheds more light on both the partial and total effects of each of these variables on environmental degradation.

On the methodological ground, this empirical study uses recently developed heterogeneous panel techniques that control for cross-sectional dependence issues, one of the main problems in panel study ${ }^{1}$ because we find that cross-sectional dependence and heterogeneity exist across African economies, and the failure to control for these issues in the estimation specification may lead to bias results. This gives a distinct look at investigating the validity of the EKC hypothesis in Sub-Sahara Africa, and, therefore, a more reliable and valid conclusion.

We structured the remaining part of this research as follows: Section 2 presents and discusses the theoretical and empirical existing literature on environment-economic growth nexus, presenting the few previous studies on green energy and ICT. Section 3 presents the methodological approach and data. The Section 4 discusses the empirical findings. The last section presents the conclusion along with implications and policy recommendations.

\section{Literature review}

Simon Kuznets in the 1960s established the relationship between environmental sustainability and income in the form of the Environmental Kuznets Curve (EKC). EKC assumes that Carbon dioxide (CO2) emissions increase in the short run during a period of economic growth, but then they start reducing as economic growth reaches a threshold in the long run. That is, economic development in the early stage, negatively affects the environment, but in the longer run results in green environmental sustainability and improved human development. Thus, the point at where $\mathrm{CO} 2$ emissions and environmental degradation start diminishing is when radical changes are no longer expected in the economy (long run). Consequently, this hypothesis leads to a Ushaped relationship between environmental degradation and income. The pioneers that tested

${ }^{1}$ Green energy investment, energy innovation, Quantile on quantile approach and 2 SLS for endogeneity. 
the EKC hypothesis are(Grossman \& Krueger, 1991; Kuznets, 1960; Stern, Common, \& Barbier, 1996; Suri \& Chapman, 1998). Recent studies like (Akbostancı, Türüt-Aş1k, \& Tunç, 2009; Desbordes \& Verardi, 2012; Kaika \& Zervas, 2013; Sarkodie \& Strezov, 2019; Shahbaz, Ozturk, Afza, \& Ali, 2013), employ various econometric techniques with different sample size to test the EKC hypothesis' robustness. These studies have however provided inconclusive and mixed findings.

Begum, Sohag, Abdullah, and Jaafar (2015) found an inverse relationship between carbon emissions and economic growth for Malaysia. The suggest energy innovation, i.e low-carbon innovations usage (green energy), mitigates environmental degradation problems for sustainable economic growth. Similarly, Kasman and Duman (2015) find a U-shaped correlation between environmental pollution and economic growth in EU economies. Cai, Sam, and Chang (2018) found a long-run relationship between economic growth, renewable energy consumption, and carbon emissions for G7 countries; the ARDL and structural break methodology used for $\mathrm{G} 7$ nations found that an effective energy-use will help to reduce $\mathrm{CO} 2$ emissions.

In MENA countries and Turkey, Farhani, Shahbaz, and Arouri (2013)and Koçak and Şarkgüneşi (2018)found CO2 emissions, energy consumption, trade openness, economic growth, and urbanization significantly influenced environmental degradation. However, Shahiduzzaman and Alam (2017) in Australia and Gill, Viswanathan, and Hassan (2018) in Malaysia respectively, found an inverted U-shaped relationship between gross domestic product (GDP) and $\mathrm{CO} 2$ emissions are found in long and short-run.

Other literature identified natural resources as a driver of environmental degradation; see (Balsalobre-Lorente, Shahbaz, Roubaud, \& Farhani, 2018; Bekun et al., 2019; Zaman, Abdullah, \& Ali, 2017). The economic dilemma of environment and natural resources pulls governments of various countries to offer subsidies for a resource -- like fuel consumption -which may increase the carbon footprint of the output. Empirically, studies have provided mixed evidence on natural resources and $\mathrm{CO} 2$ emission. For instance, Balsalobre-Lorente et al., 2018; Zhang, Wang, and Wang, (2017) conclude that natural resources exploitation improves the environment degradation. They argue that natural resource extraction or consumption through mining, agriculture, non-renewable can benefit the environmental. However, (Bekun et al., 2019; Kwakwa, Alhassan, \& Adu, 2019) conclude there is a negative impact of natural resources on the environment. According to Kwakwa, Alhassan, and Adu (2019) They argue that natural resources abundance promotes higher economic development which induces serious environmental concerns.

Other research work looks at the drivers of environmental degradation, see (Bhattacharya, Churchill, \& Paramati, 2017; Dogan \& Inglesi-Lotz, 2017; Dogan \& Ozturk, 2017; InglesiLotz \& Dogan, 2018; Zhang, Wang, \& Wang, 2017; Zoundi, 2017) They conclude that investment in green energy like renewable and non-renewable energy lead energy efficiency and thus minimize the amount of environmental degradation in society. The studies like Alberini, Bigano, Ščasný, and Zvěřinová (2018), Balsalobre-Lorente et al. (2018), Bélaïd and Youssef (2017) and Pata (2018) conclude that renewable and non-renewable energy increase environmental degradation in a society. On the other hand, Inglesi-Lotz and Dogan (2018), Zhang et al. (2017) and Bekun et al. (2019) revealed that renewable energy help to reduce environment degradation. They assume that the greater the renewable energy consumption will 
allow for sustainable economic growth due to greater efficiency in energy use thus reduce environment degradation. Chen and Lei (2018) found a negative relationship between renewable energy and the environment and a positive influence of non-renewable on the environment using quantile-ARDL methodology. However, using biomass, Sinha and Shahbaz (2018) established that environmental degradation is negatively affected by renewable energy. Overall, most of these studies agree that environmental degradation is negatively affected by non-renewable energy.

Recent studies introduced information technology to mitigate the environmental degradation generated by economic growth, see (Álvarez-Herránz, Balsalobre, Cantos, \& Shahbaz, 2017; Costantini, Crespi, Marin, \& Paglialunga, 2017; Fernando \& Wah, 2017) environmental innovation reduces the negative environmental impacts of firms as green technology creates energy efficiency, and thus decreases environmental degradation. Therefore, environmental performance improvement is driven by environmental technology.

While testing the EKC hypothesis for Sub-Saharan Africa, Inglesi-Lotz and Dogan (2018), Bhattacharya et al. (2017), Dogan and Ozturk (2017), Zoundi (2017), (Sadorsky, 2009), and (Shahbaz, Solarin, Mahmood, \& Arouri, 2013) investigate environmental degradation using $\mathrm{CO} 2$ emissions as a proxy. Other studies employed ecological footprint EF as a proxy for environmental degradation as it measures the ecological resource use and resource capacity of nations over time.; see for example Uddin, Salahuddin, Alam, and Gow (2017), Al-Mulali, Weng-Wai, Sheau-Ting, and Mohammed (2015), Ozturk, Al-Mulali, and Saboori (2016), Charfeddine and Mrabet (2017), Mrabet and Alsamara (2017), Charfeddine and Mrabet (2017), and Destek and Sarkodie (2019). Recent studies consider the environmental performance index (EPI) to investigate the environmental Kuznets curve due to the richness of the data, see Zuo, Hua, Dong, and Hao (2017), Strezov, Evans, and Evans (2017), Arbolino, Carlucci, De Simone, Ioppolo, and Yigitcanlar (2018). While EPI data is available from 2002, there is still some incomplete data, and for that reason the present study uses the standard $\mathrm{CO} 2$ emissions as a proxy for environmental degradation.

Based on this evidence, few studies have used energy innovation and green energy investment to test the EKC hypothesis. In the context of Africa, Halkos and Zisiadou (2018) and Garland, Naidoo, Sibiya, and Oosthuizen (2017) have used the environmental sustainability index to investigate EKC hypothesis for East Africa and South Africa respectively. To the best of our knowledge, no existing study has has explored the combined relationship between environmental sustainability, green energy, energy innovation, and economic growth in the context of Africa, despite merit on renewable and non-renewable energy (i.e. green energy) and energy innovation in mitigating environmental degradation in the world.

Our present study makes a case for green energy investment and energy innovation as significant drivers to mitigate environmental issues in Africa. In addition, on the methodological ground, we take a step further to account for the heterogeneity issue that may arise due to spillover effects across countries by adding a cluster-by-nation to our panel ols and quantile-on-quantile methodology. Researchers also used the lags of energy innovation and green energy variables (renewable and non-renewable energies) as instruments to solve endogeneity issue in the panel. The threshold panel regressions are estimated to endogenously determine amount of energy innovation needed in the region. Previous studies have failed to 
consider this possibility, especially as far as Sub-Saharan Africa (SSA) is concerned. DonouAdonsou (2019) highlights that methodological issues and data used have led to a lot of biased results in the African context. We are aiming at contributing towards more robust analysis in the African region.

\section{Methodology}

Our study examines the relationship between renewable energy and non-renewable energy consumption, information technology, natural resources, economic growth and environmental performance in Sub-Sahara African economies. To empirically test the EKC hypothesis we specify an econometrical model for the Sub-Sahara Africa economics for the period between 2002 and 2018. Our study finds an N-shaped empirical EKC using as additional explanatory variable renewable and non-renewable energy and information technology. Since the works of Kuznets (1960) Grossman and Krueger (1991), and Stern, Common and Barbier (1996) the link between economic growth and environmental degradation has been considered by numerous studies, as discussed in Section 2. However, Stern, Common, \& Barbier (1996) argue that environmental quality is not always guaranteed by increased economic activity. Theoretically, an increase in the growth of income per capita increases environmental degradation initially, after a turning point, and then, it starts declining with any further increase in per capita income, see Kuznets (1960). Figure 1 presents a graphical representation of the EKC hypothesis:

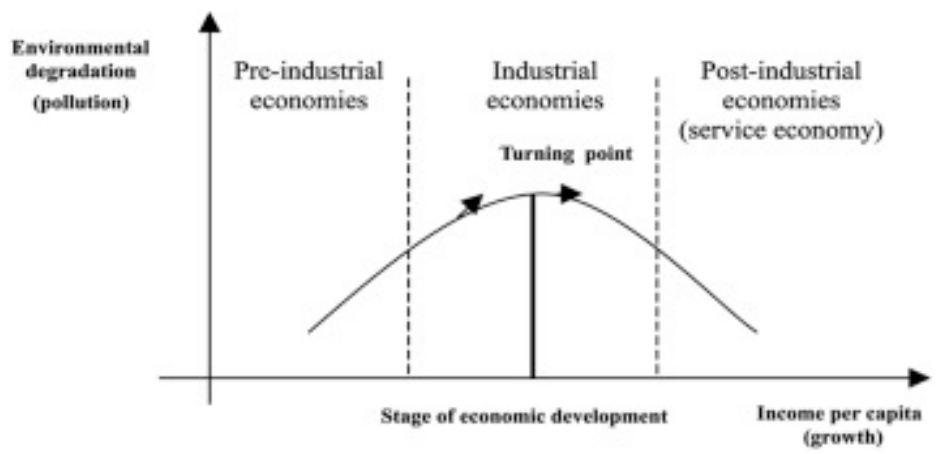

Figure 1: Theoretical inverted U-shaped EKC

Source: Sarkodie, \& Strezov (2019)

Following the theoretical relationship, we begin with the general empirical framework as described in the following specification:

$$
\begin{gathered}
C O 2_{i t}=\delta_{0}+\delta_{11} G D P p c_{i t}^{1}+\delta_{12} G D P p c_{i t}^{2}+\delta_{13} N R E N_{i t}+\delta_{14} R N E W_{i t}+\delta_{15} \text { ENGINV } \\
+\beta_{16} N N R_{i t}+\delta_{17} T O P_{i t}+\varepsilon_{i t}
\end{gathered}
$$

where $\mathrm{CO}_{i t}$ is $\mathrm{CO} 2$ emissions measured in metric tons per capita for a country $\mathrm{i}$ at year $\mathrm{t}$; economic growth is proxied by GDP per capita (constant 2010 US\$) GDPpc ${ }^{2}$ is per capita income square for a country $i$ at year t. $R N E W_{i t}$ is renewable energy consumption measured as $\%$ of total final energy consumption for country i at year t. $N R E W_{i t}$ measures used fossil fuel energy consumption ( $\%$ of total) to proxy for non-renewable energy for a country i at year $\mathrm{t}^{2}$. NNR is natural resource rent also measured by Total natural resources rents (\% of GDP) and

${ }^{2}$ We considered the summation of both renewable and non-renewable energies to form a green energy consumption. 
TOP is trade openness proxied by Trade (\% of GDP). ENGINV is energy innovation measured by Access to clean fuels and technologies for cooking ( $\%$ of population) for energy innovation to mitigate environmental degradation for every country ${ }^{3}$.

Following the EKC hypothesis which argued that an economy which achieved a higher income level can also witness a reduction in environmental pollution with continued income level growth, which eventually speeds up the process of environmental degradation, with a higher income level but with low rates of growth. Kuznets (1955) states that as a country develops the level of pollution rises, but as income growth overcomes a turning point, pollution begins to reduce. We use the model in Eq. (2) to ascertain the existence of the EKC hypothesis for SSA between 2002 and 2018. A negative coefficient for GDPpc $c_{i t}^{2}$ suggests an inverted Ushape model which validates the EKC. In addition, we expect a negative relationship between the additional explanatory variables (green energy investment and Energy Innovation) and CO2 emission in SSA. Shahbaz (2017) argue that the promotion of sources of renewable energy and the changes in energy-mix plays a direct effect in lowering $\mathrm{CO} 2$ emissions.

\subsection{Econometric methodology}

\subsubsection{Quantile-on-quantile regression approach}

This study introduces green investment, energy-innovation and natural resources into the existing literature on the environmental Kuznets model; using the new approach of Quantileon-Quantile Regression (QQ) method developed by (Sim \& Zhou, 2015). The Quantile model studies the effect of green investment, energy-innovation and natural resources on different quantiles of carbon discharged in the SSA. This new method is a combination of nonparametric evaluation as well as quantile regression. The orthodox Quantile Regression model surveys the impact of renewable energy on the different quantiles of carbon discharge. Meanwhile, the usual Linear Regression model evaluates the effect of a specific quantile of the independent variable on the dependent variable. The Quantile on Quantile Regression technique syndicates these two conventional processes to construct the relationship between quantiles of renewable energy and carbon discharge. Most existing studies implement the orthodox OLS approach to discover influencing factors for $\mathrm{CO} 2$ emissions (Fan, Liu, Wu, \& Wei, 2006). However, this type of methodology solely establishes the conditional expectation (mean value) of the dependent variable but fails to describe the entire image or description of the conditional distribution (Pires, Pereira, \& Martins, 2010).

In addition, due to the heterogeneity in SSA (Arouri, Youssef, M'henni, \& Rault, 2012; Mensah et al., 2019; Ogundipe, Alege, \& Ogundipe, 2014), the relationships present among several technological development and $\mathrm{CO} 2$ secretions are probable to carry out discriminately at different quantiles (i.e. to perform otherwise across emitters with distinct degrees of emissions). As such, the quantile regression Khalifa, Othman, and Hussainey (2018) permits the coefficients to differ for different quantiles, and has unique benefits of detecting the difference within the impact of green investment and energy innovation on the distribution of $\mathrm{CO} 2$ emissions. 
Furthermore, the quantile regression technique is also beneficial for tackling issues that may significantly affect the accuracy of estimation, which include heteroscedasticity, outliers, and unobserved heterogeneity (Alsayed, Isa, Kun, \& Manzi, 2019; Distante, Petrella, \& Santoro, 2018). This paper adopts the quantile regression to comprehensively explore the relationship between green investment, energy-innovation and natural resources and $\mathrm{CO} 2$ emissions at several quantiles of $\mathrm{CO} 2$ emissions. The econometric model below presents the conditional quantile function of the panel data:

$y_{i t}=\left(\tau x_{i t}\right)=x_{i t}^{\prime} \varphi(\tau)+\mu_{\tau i}, 0<\tau<1$

$\operatorname{Quant}_{\tau}\left(y_{i t} / x_{i t}\right)=x_{i t} \varphi_{o}$

Note that $y_{i t}\left(\tau x_{i t}\right)$ is the dependent variable for $\tau$ th quantile; the vector of explanatory variables is $x_{i t}$; $\tau$ represents the quantiles, and the coefficients for the $\tau$ th quantile is $\varphi(\tau)$ : Also, the $\tau$ th of the dependent variable is further defined as $\operatorname{Quant}_{\tau}\left(y_{i t} / x_{i t}\right)$ and $\varphi_{o}$ represents the quantile regression estimator. This can be further simplified as follows:

$\min \sum_{y_{i t} \geq x_{i t}^{\prime} \varphi} \tau / y_{i t}-x_{i t}^{\prime} \varphi /+\sum_{y_{i t} \geq x_{i t}^{\prime} \varphi}(1-\tau) y_{i t}-x_{i t}^{\prime} \varphi(\tau)$

Where $\tau$ equals to different values and obtained from different parameter estimates: $t$ represents the number of years and $i$ the number of countries; $w_{i t}$ is the load of the $i^{\text {th }}$ metropolis within the $t^{\text {th }}$ year, which is consistent with the linear quantile loss function in (Koenker \& Bassett Jr, 1978; Okada \& Samreth, 2012). Following quantile equation above, the empirical model to investigate the relationship between green energy consumption, energy innovation, economic growth and $\mathrm{CO} 2$ emission is defined as:

$$
\begin{aligned}
& \text { Quant }_{\tau}\left(\mathrm{CO}_{i t}\right) \\
& =\left(\varphi_{\tau}\right)+\varphi_{\tau 1} G D P p c_{i t}^{1}+\varphi_{\tau 2} G D P p c_{i t}^{2}+\varphi_{\tau 3} N R E N_{i t}+\varphi_{\tau 4} R N E W_{i t} \\
& +\varphi_{\tau 5} \text { ENGINV }+\varphi_{\tau 6} N N R_{i t}+\varphi_{\tau 7} T O P_{i t}+\varepsilon_{i t} \text {, }
\end{aligned}
$$

Where Quant $_{\tau}$ is a parameter of $\tau$ th quantile in $\mathrm{CO} 2$ emission and $\left(\varphi_{\tau}\right)$ for constants term. $\varphi_{\tau 1}, \varphi_{\tau 2}, \varphi_{\tau 3}, \varphi_{\tau 4}, \varphi_{\tau 5}, \varphi_{\tau 6}$ and $\varphi_{\tau 7}$ are parameters of the $\tau$ th quantile for GDPpc(GDP per capita at constant prices USD), GDPpc ${ }^{2}$ (GDP per capita square at constant prices USD), NREW(non-renewable energy consumption), RNEW(renewable energy consumption), ENGIVN(energy innovation) and NNR (natural resource rent) and TOP(trade openness) respectively.

\section{Significant findings}

\subsection{Variables, data, and variations}

Although we acknowledge that the sample includes a relative short-time series for the study of economic growth, our study utilizes the richness in panel data. The exogenous variables used are described as follows. GDP per capita (constant 2010 US\$). $R N E W_{i t}$ was utilized to measure for income level, and it is sourced from World bank WDI (Ocal \& Aslan, 2013). To proxy for energy innovation we use the Access to clean fuels and technologies for cooking (\% of population) from WDI. To proxy for renewable energy we use the renewable energy consumption as a \% of total final energy consumption, while we use fossil fuel energy consumption ( $\%$ of total) to proxy for non-renewable energy. We also include trade openness 
(exports and imports as a proportion of GDP) as a control variable, see Mutascu (2018). The dependent variable is $\mathrm{CO} 2$ emissions measured in metric tons per capita; all these latter variables are sourced from World Bank WDI (2020) see, Bhattacharya et al. (2017). The table below summarises descriptive statistics for the variables used in the study:

Table1: Descriptive Statistics

\begin{tabular}{|c|c|c|c|c|}
\hline Variable & Description & Unit of Measurement & Mean & Std. Dev. \\
\hline $\mathrm{CO} 2$ & CO2 emissions & $\begin{array}{l}\mathrm{CO} 2 \text { emissions (in metric tons per } \\
\text { capita) }\end{array}$ & 421.1715 & 313.2917 \\
\hline GDPpc & GDP per capita & GDPpc is calculated as GDP/Pop & 1940.977 & 2759.984 \\
\hline GDPpc2 & $\begin{array}{l}\text { GDP per capita } \\
\text { Square }\end{array}$ & $\begin{array}{l}\text { GDPpc is calculated as GDP/Pop } \\
\text { Square }\end{array}$ & $1.14 \mathrm{e}+07$ & $3.52 e+07$ \\
\hline NREN & $\begin{array}{l}\text { Renewable } \\
\text { energy }\end{array}$ & $\begin{array}{l}\text { Renewable energy consumption } \\
\text { (\% of total final energy } \\
\text { consumption }\end{array}$ & 69.52457 & 24.75526 \\
\hline RNEW & $\begin{array}{l}\text { Non-renewable } \\
\text { energy }\end{array}$ & $\begin{array}{l}\text { Fossil fuel energy consumption ( } \% \\
\text { of total) }\end{array}$ & 27.95567 & 22.66346 \\
\hline ENGINV & $\begin{array}{l}\text { Energy } \\
\text { Innovation }\end{array}$ & $\begin{array}{l}\text { Access to clean fuels and } \\
\text { technologies for cooking ( } \% \text { of } \\
\text { population) }\end{array}$ & 18.9063 & 24.48617 \\
\hline NNR & Natural Resource & $\begin{array}{l}\text { Total natural resources rents ( } \% \text { of } \\
\text { GDP) }\end{array}$ & 11.32569 & 10.98626 \\
\hline TOP & Trade Openness & Exports and imports ( $\%$ of GDP) & 69.07661 & 35.77887 \\
\hline
\end{tabular}

The description of the dependent and independents variables in term of measurements, means, standard deviation in Table 1. CO2 emissions as a proportion of GDP for various regions is compared with emissions for Sub-Sahara Africa in Fig 1. CO2 emissions for each region are still high, however the trend in the majority of the regions is downward sloping, which indicates that an increase in GDP mitigates environmental degradation; see for example North America, Europe, Asia Oceans, and OECD Asia Oceania. However, for the case of Africa, the trend is not decreasing, suggesting that increases in GDP increase environmental degradation. Fig 2 presents an analysis of the share of renewable energy for each region. Renewable energy consumption in the Middle East is the lowest, followed by Non-OECD Europe and Eurasia, China, OECD Total, Non-OECD Asia, Non-OECD Americas. Interestingly, the percentage of renewable energy in Africa is the highest among the regions for the year 2018.

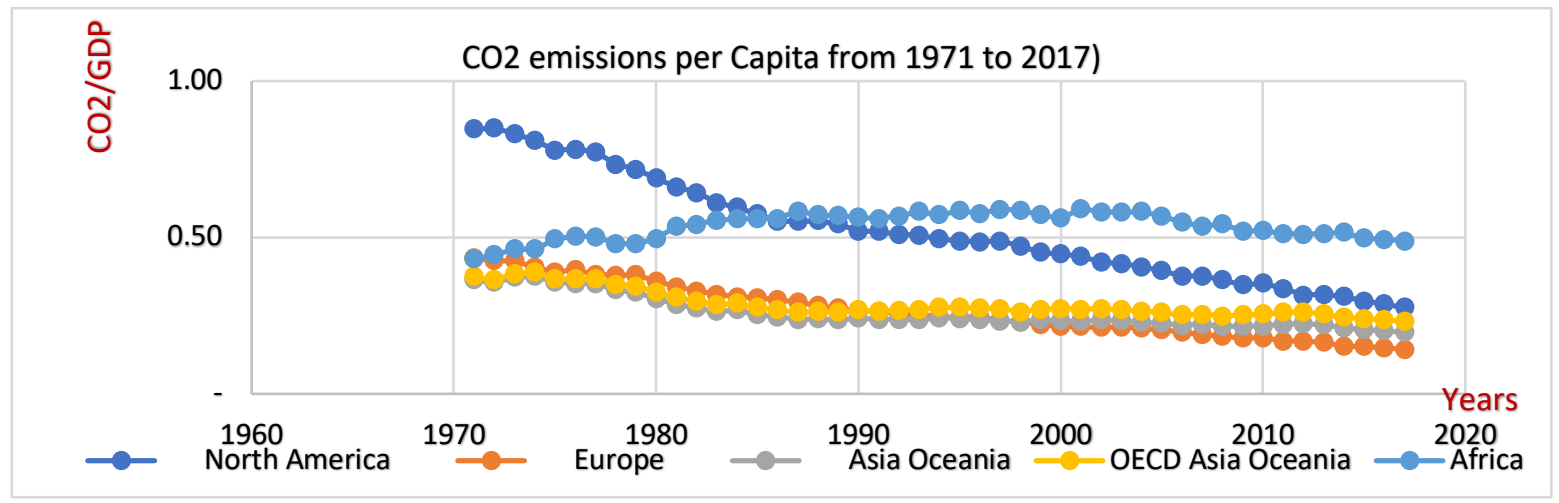

Fig. 1. CO2 Emissions from Fuel Combustion [IEA, 2019], Sources: IEA (2019), CO2 Emissions from Fuel Combustion. 


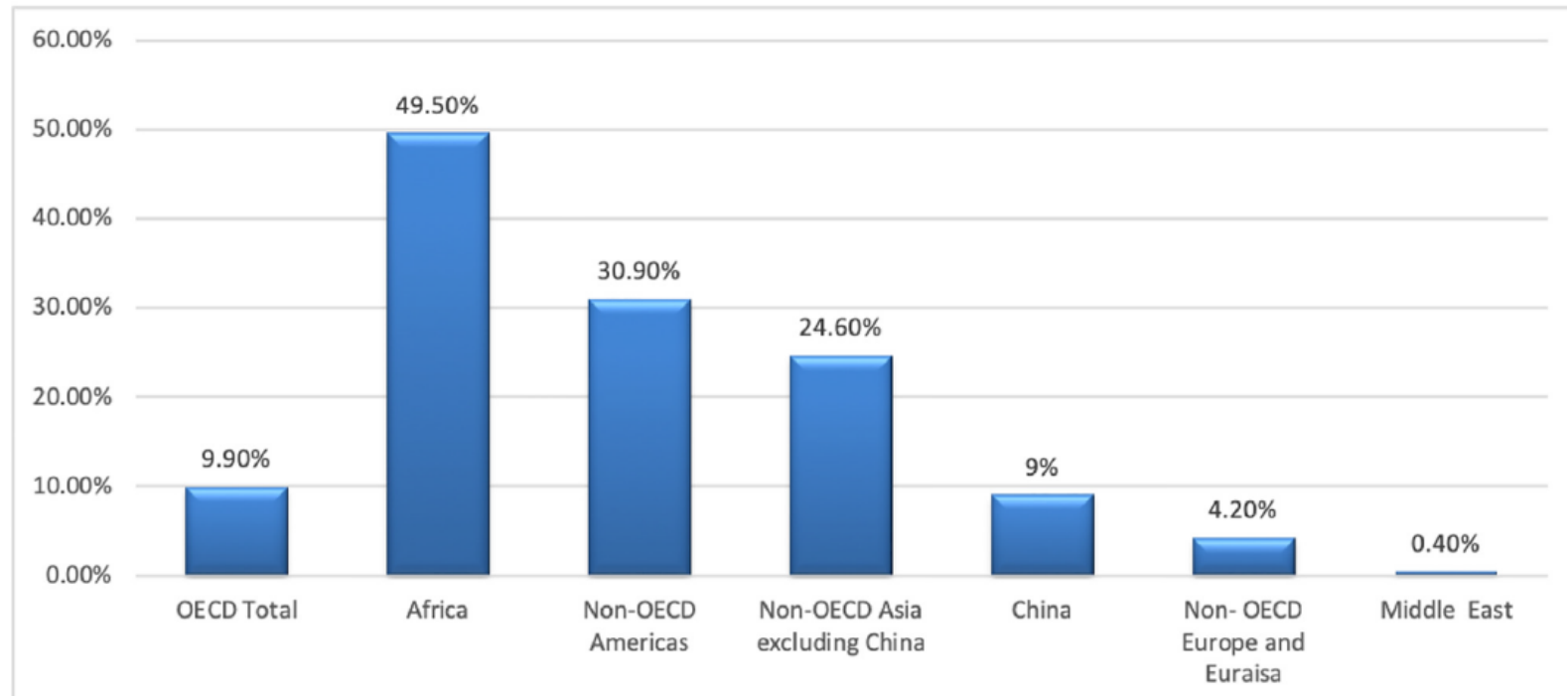

Fig. 2. Share of Renewables energy regional specific TPES [IEA, 2018]

\subsection{Results}

Table 2 show the results of panel ordinary least square, quantile on quantile estimators and endogeneity test (2sls). The first column is POLS, second column is POLS with cluster which captured the issue of heteroscedasticity in the panel, third, fourth, fifty and six column are quantile estimators for $0.25,0.50,0.75$ and 0.90 quantiles respectively and the eigth column is 2 sls result.

Table 2

Long-run estimation for Quantile Regression

\begin{tabular}{|c|c|c|c|c|c|c|c|}
\hline \multirow{2}{*}{$\begin{array}{l}\mathrm{DV}=\mathrm{CO} 2 \\
\text { Variable }\end{array}$} & \multicolumn{2}{|c|}{ Panel OLS } & \multicolumn{4}{|c|}{ Quantile on Quantile Estimation } & \multirow{2}{*}{$\begin{array}{l}\text { Endo } \\
\underline{\underline{2 s l s}}\end{array}$} \\
\hline & POLS & POLScluster & qreg25 & qreg50 & qreg75 & qreg90 & \\
\hline GDPpc & $\begin{array}{c}0.0001 \\
{[0.0001]}\end{array}$ & $\begin{array}{c}0.0001 \\
{[0.0001]}\end{array}$ & $\begin{array}{c}0.0001 \\
{[0.0001]}\end{array}$ & $\begin{array}{c}0.0001 \\
{[0.0001]}\end{array}$ & $\begin{array}{c}0.0001 \\
{[0.0001]}\end{array}$ & $\begin{array}{c}0.0001 \\
{[0.0001]}\end{array}$ & $\begin{array}{c}0.0001 \\
{[0.0001]}\end{array}$ \\
\hline GDPpc2 & $\begin{array}{c}0.352 \\
{[0.317]}\end{array}$ & $\begin{array}{c}0.352 \\
{[0.410]}\end{array}$ & $\begin{array}{c}0.261 \\
{[0.295]}\end{array}$ & $\begin{array}{c}0.756^{* *} \\
{[0.277]}\end{array}$ & $\begin{array}{c}0.359 \\
{[0.386]}\end{array}$ & $\begin{array}{c}-0.152 \\
{[0.152]}\end{array}$ & $\begin{array}{c}0.152 \\
{[0.130]}\end{array}$ \\
\hline NREW & $\begin{array}{c}0.521 * * * \\
{[0.156]}\end{array}$ & $\begin{array}{c}0.521 * * \\
{[0.178]}\end{array}$ & $\begin{array}{l}0.359 * \\
{[0.152]}\end{array}$ & $\begin{array}{c}0.522 * * \\
{[0.177]}\end{array}$ & $\begin{array}{c}0.265 \\
{[0.150]}\end{array}$ & $\begin{array}{c}-0.104 \\
{[0.082]}\end{array}$ & $\begin{array}{c}0.612 * * * \\
{[0.6457]}\end{array}$ \\
\hline RENW & $\begin{array}{c}0.206 \\
{[0.127]}\end{array}$ & $\begin{array}{c}0.206 \\
{[0.162]}\end{array}$ & $\begin{array}{c}0.263 \\
{[0.172]}\end{array}$ & $\begin{array}{c}0.492^{*} \\
{[0.211]}\end{array}$ & $\begin{array}{c}0.095 \\
{[0.131]}\end{array}$ & $\begin{array}{c}-0.147^{*} \\
{[0.076]}\end{array}$ & $\begin{array}{c}-0.499 * * * \\
{[0.038]}\end{array}$ \\
\hline ENGINV & $\begin{array}{c}0.005 \\
{[0.209]}\end{array}$ & $\begin{array}{c}0.005 \\
{[0.262]}\end{array}$ & $\begin{array}{c}0.082 \\
{[0.128]}\end{array}$ & $\begin{array}{c}0.075 \\
{[0.176]}\end{array}$ & $\begin{array}{c}0.002 \\
{[0.194]}\end{array}$ & $\begin{array}{c}-0.152 \\
{[0.130]}\end{array}$ & $\begin{array}{c}-0.366^{* * *} \\
{[0.039]}\end{array}$ \\
\hline NNR & $-0.020 * *$ & $-0.020 *$ & -0.005 & -0.012 & -0.012 & 0.003 & -0.006 \\
\hline
\end{tabular}




\begin{tabular}{|c|c|c|c|c|c|c|c|}
\hline & [0.007] & [0.010] & [0.004] & [0.006] & [0.018] & [0.005] & [0.004] \\
\hline TOP & $\begin{array}{c}0.009 * * \\
{[0.003]}\end{array}$ & $\begin{array}{l}0.009 * \\
{[0.004]}\end{array}$ & $\begin{array}{c}0.001 \\
{[0.003]}\end{array}$ & $\begin{array}{c}0.0001 \\
{[0.003]}\end{array}$ & $\begin{array}{c}0.004 \\
{[0.003]}\end{array}$ & $\begin{array}{c}0.001 \\
{[0.002]}\end{array}$ & $\begin{array}{c}-0.001 \\
{[0.002]}\end{array}$ \\
\hline _cons & $\begin{array}{c}-0.105 \\
{[0.381]}\end{array}$ & $\begin{array}{c}-0.105 \\
{[0.514]}\end{array}$ & $\begin{array}{c}-0.658^{*} \\
{[0.274]}\end{array}$ & $\begin{array}{c}0.908 * * \\
{[0.316]}\end{array}$ & $\begin{array}{c}1.233 * * * \\
{[0.368]}\end{array}$ & $\begin{array}{c}1.388^{* * *} \\
{[0.195]}\end{array}$ & $\begin{array}{c}0.395^{* *} \\
{[0.144]}\end{array}$ \\
\hline $\begin{array}{l}\text { Fixed } \\
\text { effect }\end{array}$ & Yes & Yes & Yes & Yes & Yes & Yes & Yes \\
\hline Cluster & Yes & Yes & Yes & Yes & Yes & Yes & Yes \\
\hline AIC & -76.22 & -76.22 & -76.22 & -76.22 & -76.22 & -76.22 & -76.22 \\
\hline $\mathrm{BIC}$ & -44.91 & -44.91 & -44.91 & -44.91 & -44.91 & -44.91 & -44.91 \\
\hline Chi2 & 50.55 & & 50.55 & 62.172 & 73.836 & 90.525 & 141.9 \\
\hline N Obs & 375 & 375 & 375 & 375 & 375 & 375 & 375 \\
\hline
\end{tabular}

To identify the statistical power of the quantile on the quantile approach, this study compared the results of the panel ordinary least square model with quantile estimators in Table 2 . The results in table 2 confirm a positive relationship between economic growth and carbon emissions in all the models. This indicates that an increase in economic growth increases environmental degradation in the selected sample. Similarly, the study confirms a positive relationship between the square of GDPpc and $\mathrm{CO} 2$ emission from quantile 0.25 to 0.75 but turned negative at the upper quantile of 0.90 . This indication of this that, from quantile 0.25 to 0.75 and POLS, we confirmed the N-shaped relationship. However, the upper quantile of 0.90 validates the EKC hypothesis in SSA. It also indicates that SSA has a U-shaped EKC for CO2 emissions at the upper quantile of 0.90. Relying on panel OLS will fail us to identify such an important contribution. Our result is in line with the findings of Shahiduzzaman and Alam (2017).

In table 2 again, the study found that NREW (non-renewable energy consumption) has a positive relationship and significant on $\mathrm{CO} 2$ emission in the linear term, NREW directly affected $\mathrm{CO} 2$ emissions at quantile 0.25 , middle quantile 0.50 , quantile 0.75 including OLS estimator. Meanwhile, the positive effect is seeing in terms of GDPpc square. This indicates that NREW increases CO2 emissions by $0.352,0.261,0.756$ and 0.359 million tons respectively in POLS Cluster, and from 0.25 to 0.75 the quantiles. Then again, the upper quantile of 0.90 confirmed a negative relationship with non-renewable energy consumption and $\mathrm{CO} 2$ emission in SSA. At 0.90 quantile, a unit increase in non-renewable energy consumption decrease $\mathrm{CO} 2$ emission by 0.104 million tons. Our quantile methodology confirmed that SSA may experience environmental degradation at lower quantiles, however, green energy (non-renewable energy consumption) will help to reduce SSA's environmental degradation at the upper quantile. For Sub-Sahara Africa, the results of the 2SLS estimation are approximately similar to that of 0.90 quantiles. This finding is similar to that of (Awodumi $\&$ Adewuyi, 2020) that confirmed the non-renewable energy consumption helps to reduce $\mathrm{CO} 2$ emissions in Ngeria and suggested consumption of non-renewable energy may help to reduce the amount of $\mathrm{CO} 2$ emission in any society. 
In the model with renewable energy consumption, for the Sub-Sahara region, the coefficient calculated by POLS, POLS with cluster and the first three quantiles of quantile on quantile models found a significant positive relationship between $\mathrm{CO} 2$ emissions and renewable energy consumption in SSA. The elasticity coefficients of CO2 to RENW are $0.206,0.206,0.263$, 0.492 and 0.095 respectively. Effectively, a 1\% rise in RENW increased CO2 by around 0.206 , $0.206,0.263,0.492$ and 0.095 million tons respectively. Conversely, at 0.90 quantile, there is a positive relationship between $\mathrm{CO} 2$ and RENW in SSA. This implies that a unit increase in renewable energy consumption reduces $\mathrm{CO} 2$ emission by 0.147 million tons. The quantile methodology confirmed that SSA may witness environmental degradation at lower quantiles, nevertheless, green energy (non-renewable energy consumption) will help to reduce the rate of environmental degradation in SSA at the upper quantile. This result was consistent with the fact that the economic impact of a policy varies across quantile which OLS has failed to address. A similar result was found in our 2 sls model which confirmed a negative and significant relationship between renewable energy consumption and $\mathrm{CO} 2$ emission in SSA. This finding support that of Inglesi-Lotz and Dogan (2018), Zhang et al. (2017) and Bekun et al. (2019) that confirmed the contribution of renewable energy to $\mathrm{CO} 2$ emissions and suggested renewable energy consumption help reduce the amount of $\mathrm{CO} 2$ emissions in a society.

Regarding energy innovation in SSA, the coefficient calculated by POLS, POLS with cluster and the first three quantiles of quantile-on-quantile models confirmed a positive correlation between energy innovation and CO2 emission in SSA. Our POLS, POLS with cluster and the first three quantiles of quantile-on-quantile estimates, found that energy innovation increases CO2 emissions by $0.005,0.005,0.082,0.075$ and 0.002 million tons respectively for every 1 dollar increase in energy innovation. The indication of this is that innovation drives economic growth and therefore economic activities increased the use of highly polluting energy resources in SSA. However, in the last quantile of 0.90 , energy innovation reduces $\mathrm{CO} 2$ emission significantly by 0.152 million tons. This study takes care of the endogeneity problem in a panel through 2sls, using the lags of renewable energy consumption, non-renewable energy consumption, and energy innovation as the instruments in our 2sls model. We confirmed that energy innovation reduces $\mathrm{CO} 2$ emission significantly by 0.366 million tons in SSA. Our findings support Costantini, Crespi, Marin, \& Paglialunga, 2017. We suggest environmental policy targeted towards enhancing innovation in emission-reducing technology at both the public and private levels to mitigate environmental degradation problems in SSA.

Finally, for SSA, the empirical findings of POLS, POLS with cluster and all the quantile-onquantile models on average suggest that a negative correlation between natural resource abundance and $\mathrm{CO} 2$ emission in SSA. This indicates that natural resource abundance helps to reduce environmental degradation in the region. Our finding is in line with that of Bekun et al., (2019). Conversely, the elasticities of CO2 emissions with respect to trade openness is positive in all the models. This indicates that trade openness increases CO2 emission in SSA. This is also support the findings of Balsalobre-Lorente, Shahbaz, Roubaud, \& Farhani, (2018). We suggest a policy to stimulate the use of green energy both renewable and non-renewable sources and invest more in energy innovation and efficient use of natural resource so as to reach lower level of emissions in SSA. 
Table 5

Results of Threshold Values

\begin{tabular}{lcl}
\hline S/No & Test & enginv \\
\hline 1 & $\gamma$ & 2.804 \\
2 & C & 53.66 \\
3 & AIC & 3844.15 \\
4 & BIC & 3857.96 \\
\hline
\end{tabular}

Table 5 indicates the optimal thresholds (EXPLAIN MORE). For enginv the optimal threshold 54 percent in SSA. The indication of this is that these thresholds suggest that to act positively on the level of growth, SSA countries need atleast 54 percent of their population to have access to energy innovation in order to reduce the amount of $\mathrm{CO} 2$ emission in the region. We suggest a policy toward improvement in energy innovation above the estimated threshold in SSA.

\section{Conclusion}

This paper investigates the moderating role of green energy and energy-innovation in Environmental Kuznets in SSA from the 1980-2018 period. The study includes green investment, energy innovation and natural resource rent to the existing studies on the EKC hypothesis. Following the argument of Alvarez-Herranz, Balsalobre-Lorente, Shahbaz, and Cantos (2017) argued that energy innovation mitigates environmental degradation problem in society. However, our results confirmed that energy innovation help to reduce environmental degradation in SSA. Hence, implementing a policy to encourage energy innovation above the threshold estimated will go a long way to improve environmental malaise in SSA. This also makes a case that green energy consumption such as consumption in renewable and nonrenewable energy consumption will improve energy efficiency and thus reduce the amount of pollution in the region of Africa following the conclusion of Dogan and Ozturk (2017) nonrenewable and Alvarez-Herranz et al. (2017) for renewable energy. Our econometrics analysis supports these findings. However, our study combined both renewable and non-renewable to form green energy consumption and give inference on quantiles bases and also estimate the minimum threshold point of investment on the green that the region could be safe which has not been covered the existing literature. To environmental sustainability, a policy should be targeted towards encouraging the consumption of renewable energy sources for domestic production in SSA. Moreover, the study found income to be positive and significant on the environment and the income squared is negatively related with $\mathrm{CO} 2$ emission, therefore established a U-shaped EKC relationship in SSA.

Additionally, we found that natural resource abundance decreases CO2 emission in the SSA. Even though, scholars have argued that the extraction and consumption of some natural resources induce environmental pollution. However, conservation of energy such as oil, coal and natural gas will reduce air environmental pollution. Surprisingly, many African countries are enriched with large, vast and untapped natural resources. The proper conservation of these resources will help to reduce pollution and mitigate respiratory health issues caused by pollution. Besides, the use of alternative forms of energy like renewable energy when possible may diminish environmental degradation in the region. 
Trade openness increases environmental pollution in SSA. This result supports the first phase of environmental Kuznets which argues that the increase in output will increase environmental pollution. This is no surprise since Africa is a resource-based economy in which the major trade activities includes activities like mining and gas flaring by foreign investors are the candidate for environmental degradation. However, encouraging the importation of energy-efficient technologies could reduce $\mathrm{CO} 2$ emission in the region.

We, therefore, conclude that green energy investment, energy innovation, and conservation of natural resources will help to mitigate environmental degradation in SSA in the long run. Policies should be targeted towards encouraging the consumption of green energy, more investment in energy innovation beyond the estimated threshold will save the region from pollution problems.

\section{Reference}

Adzawla, W., Sawaneh, M., \& Yusuf, A. M. (2019). Greenhouse gasses emission and economic growth nexus of sub-Saharan Africa. Scientific African, 3, e00065.

Akbostancı, E., Türüt-Aşık, S., \& Tunç, G. i̇. (2009). The relationship between income and environment in Turkey: is there an environmental Kuznets curve? Energy Policy, 37(3), 861-867.

Al-Mulali, U., Weng-Wai, C., Sheau-Ting, L., \& Mohammed, A. H. (2015). Investigating the environmental Kuznets curve (EKC) hypothesis by utilizing the ecological footprint as an indicator of environmental degradation. Ecological Indicators, 48, 315-323.

Alberini, A., Bigano, A., Ščasný, M., \& Zvěřinová, I. (2018). Preferences for energy efficiency vs. renewables: what is the willingness to pay to reduce $\mathrm{CO} 2$ emissions? Ecological Economics, 144, 171-185.

Alsayed, A. R., Isa, Z., Kun, S. S., \& Manzi, G. (2019). Quantile Regression to Tackle the Heterogeneity on the Relationship Between Economic Growth, Energy Consumption, and CO 2 Emissions. Environmental Modeling \& Assessment, 1-8.

Alvarez-Herranz, A., Balsalobre-Lorente, D., Shahbaz, M., \& Cantos, J. M. (2017). Energy innovation and renewable energy consumption in the correction of air pollution levels. Energy Policy, 105, 386-397.

Álvarez-Herránz, A., Balsalobre, D., Cantos, J. M., \& Shahbaz, M. (2017). Energy innovations-GHG emissions nexus: Fresh empirical evidence from OECD countries. Energy Policy, 101, 90-100.

Arbolino, R., Carlucci, F., De Simone, L., loppolo, G., \& Yigitcanlar, T. (2018). The policy diffusion of environmental performance in the European countries. Ecological Indicators, 89, 130-138.

Arouri, M. E. H., Youssef, A. B., M'henni, H., \& Rault, C. (2012). Energy consumption, economic growth and $\mathrm{CO} 2$ emissions in Middle East and North African countries. Energy Policy, 45, 342-349.

Awodumi, O. B., \& Adewuyi, A. O. (2020). The role of non-renewable energy consumption in economic growth and carbon emission: Evidence from oil producing economies in Africa. Energy Strategy Reviews, 27, 100434.

Balsalobre-Lorente, D., Shahbaz, M., Roubaud, D., \& Farhani, S. (2018). How economic growth, renewable electricity and natural resources contribute to $\mathrm{CO} 2$ emissions? Energy Policy, 113, 356-367.

Begum, R. A., Sohag, K., Abdullah, S. M. S., \& Jaafar, M. (2015). CO2 emissions, energy consumption, economic and population growth in Malaysia. Renewable and Sustainable Energy Reviews, 41, 594-601.

Bekun, F. V., Alola, A. A., \& Sarkodie, S. A. (2019). Toward a sustainable environment: Nexus between $\mathrm{CO} 2$ emissions, resource rent, renewable and nonrenewable energy in 16-EU countries. Science of The Total Environment, 657, 1023-1029. 
Bélaïd, F., \& Youssef, M. (2017). Environmental degradation, renewable and non-renewable electricity consumption, and economic growth: Assessing the evidence from Algeria. Energy Policy, 102, 277-287.

Bhattacharya, M., Churchill, S. A., \& Paramati, S. R. (2017). The dynamic impact of renewable energy and institutions on economic output and $\mathrm{CO} 2$ emissions across regions. Renewable Energy, 111, 157-167.

Cai, Y., Sam, C. Y., \& Chang, T. (2018). Nexus between clean energy consumption, economic growth and $\mathrm{CO} 2$ emissions. Journal of Cleaner Production, 182, 1001-1011.

Charfeddine, L., \& Mrabet, Z. (2017). The impact of economic development and social-political factors on ecological footprint: A panel data analysis for 15 MENA countries. Renewable and Sustainable Energy Reviews, 76, 138-154.

Chen, W., \& Lei, Y. (2018). The impacts of renewable energy and technological innovation on environment-energy-growth nexus: New evidence from a panel quantile regression. Renewable Energy, 123, 1-14.

Costantini, V., Crespi, F., Marin, G., \& Paglialunga, E. (2017). Eco-innovation, sustainable supply chains and environmental performance in European industries. Journal of Cleaner Production, 155, 141-154.

Desbordes, R., \& Verardi, V. (2012). Refitting the Kuznets curve. Economics letters, 116(2), 258-261.

Destek, M. A., \& Sarkodie, S. A. (2019). Investigation of environmental Kuznets curve for ecological footprint: the role of energy and financial development. Science of The Total Environment, 650, 2483-2489.

Distante, R., Petrella, I., \& Santoro, E. (2018). Gibrat's law and quantile regressions: An application to firm growth. Economics letters, 164, 5-9.

Dogan, E., \& Inglesi-Lotz, R. (2017). Analyzing the effects of real income and biomass energy consumption on carbon dioxide ( $\mathrm{CO} 2$ ) emissions: empirical evidence from the panel of biomass-consuming countries. Energy, 138, 721-727.

Dogan, E., \& Ozturk, I. (2017). The influence of renewable and non-renewable energy consumption and real income on CO 2 emissions in the USA: evidence from structural break tests. Environmental Science and Pollution Research, 24(11), 10846-10854.

Donou-Adonsou, F. (2019). Technology, education, and economic growth in Sub-Saharan Africa. Telecommunications policy, 43(4), 353-360.

Fan, Y., Liu, L.-C., Wu, G., \& Wei, Y.-M. (2006). Analyzing impact factors of $\mathrm{CO} 2$ emissions using the STIRPAT model. Environmental Impact Assessment Review, 26(4), 377-395.

Farhani, S., Shahbaz, M., \& Arouri, M. E. H. (2013). Panel analysis of CO2 emissions, GDP, energy consumption, trade openness and urbanization for MENA countries.

Fernando, Y., \& Wah, W. X. (2017). The impact of eco-innovation drivers on environmental performance: Empirical results from the green technology sector in Malaysia. Sustainable Production and Consumption, 12, 27-43.

Garland, R. M., Naidoo, M., Sibiya, B., \& Oosthuizen, R. (2017). Air quality indicators from the Environmental Performance Index: potential use and limitations in South Africa. Clean Air Journal= Tydskrif vir Skoon Lug, 27(1), 33-41.

Gill, A. R., Viswanathan, K. K., \& Hassan, S. (2018). A test of environmental Kuznets curve (EKC) for carbon emission and potential of renewable energy to reduce green house gases (GHG) in Malaysia. Environment, Development and Sustainability, 20(3), 1103-1114.

Grossman, G. M., \& Krueger, A. B. (1991). Environmental impacts of a North American free trade agreement. Retrieved from

Halkos, G., \& Zisiadou, A. (2018). Relating environmental performance with socioeconomic and cultural factors. Environmental Economics and Policy Studies, 20(1), 69-88.

Inglesi-Lotz, R., \& Dogan, E. (2018). The role of renewable versus non-renewable energy to the level of $\mathrm{CO} 2$ emissions a panel analysis of sub-Saharan Africa's Big 10 electricity generators. Renewable Energy, 123, 36-43. 
Kaika, D., \& Zervas, E. (2013). The Environmental Kuznets Curve (EKC) theory-Part A: Concept, causes and the $\mathrm{CO} 2$ emissions case. Energy Policy, 62, 1392-1402.

Kasman, A., \& Duman, Y. S. (2015). CO2 emissions, economic growth, energy consumption, trade and urbanization in new EU member and candidate countries: a panel data analysis. Economic Modelling, 44, 97-103.

Khalifa, M., Othman, H. B., \& Hussainey, K. (2018). The effect of ex ante and ex post conservatism on the cost of equity capital: A quantile regression approach for MENA countries. Research in International Business and Finance, 44, 239-255.

Koçak, E., \& Şarkgüneşi, A. (2018). The impact of foreign direct investment on CO 2 emissions in Turkey: new evidence from cointegration and bootstrap causality analysis. Environmental Science and Pollution Research, 25(1), 790-804.

Koenker, R., \& Bassett Jr, G. (1978). Regression quantiles. Econometrica: journal of the Econometric Society, 33-50.

Kuznets, S. (1960). Economic growth of small nations. In Economic consequences of the size of nations (pp. 14-32): Springer.

Kwakwa, P. A., Alhassan, H., \& Adu, G. (2019). Effect of natural resources extraction on energy consumption and carbon dioxide emission in Ghana. International Journal of Energy Sector Management.

Mensah, I. A., Sun, M., Gao, C., Omari-Sasu, A. Y., Zhu, D., Ampimah, B. C., \& Quarcoo, A. (2019). Analysis on the nexus of economic growth, fossil fuel energy consumption, $\mathrm{CO} 2$ emissions and oil price in Africa based on a PMG panel ARDL approach. Journal of Cleaner Production, 228, 161-174.

Monyei, C. G., Adewumi, A. O., Obolo, M. O., \& Sajou, B. (2018). Nigeria's energy poverty: Insights and implications for smart policies and framework towards a smart Nigeria electricity network. Renewable and Sustainable Energy Reviews, 81, 1582-1601.

Mrabet, Z., \& Alsamara, M. (2017). Testing the Kuznets Curve hypothesis for Qatar: A comparison between carbon dioxide and ecological footprint. Renewable and Sustainable Energy Reviews, 70, 1366-1375.

Ocal, O., \& Aslan, A. (2013). Renewable energy consumption-economic growth nexus in Turkey. Renewable and Sustainable Energy Reviews, 28, 494-499.

Ogundipe, A., Alege, P. O., \& Ogundipe, O. (2014). Income heterogeneity and environmental Kuznets curve in Africa. Journal of Sustainable Development, 7(4).

Okada, K., \& Samreth, S. (2012). The effect of foreign aid on corruption: A quantile regression approach. Economics letters, 115(2), 240-243.

Ozturk, I., Al-Mulali, U., \& Saboori, B. (2016). Investigating the environmental Kuznets curve hypothesis: the role of tourism and ecological footprint. Environmental Science and Pollution Research, 23(2), 1916-1928.

Pata, U. K. (2018). Renewable energy consumption, urbanization, financial development, income and CO2 emissions in Turkey: testing EKC hypothesis with structural breaks. Journal of Cleaner Production, 187, 770-779.

Pires, P., Pereira, J. P., \& Martins, L. F. (2010). The complete picture of credit default swap spreads-a quantile regression approach. Available at SSRN 1125265.

Prasad, J., \& Samikannu, R. (2018). Barriers to implementation of smart grids and virtual power plant in sub-saharan region-focus Botswana. Energy Reports, 4, 119-128.

Sadorsky, P. (2009). Renewable energy consumption, $\mathrm{CO} 2$ emissions and oil prices in the G7 countries. Energy Economics, 31(3), 456-462.

Sarkodie, S. A., \& Strezov, V. (2019). A review on environmental Kuznets curve hypothesis using bibliometric and meta-analysis. Science of The Total Environment, 649, 128-145.

Shahbaz, M., Ozturk, I., Afza, T., \& Ali, A. (2013). Revisiting the environmental Kuznets curve in a global economy. Renewable and Sustainable Energy Reviews, 25, 494-502. 
Shahbaz, M., Solarin, S. A., Mahmood, H., \& Arouri, M. (2013). Does financial development reduce $\mathrm{CO} 2$ emissions in Malaysian economy? A time series analysis. Economic Modelling, 35, 145152.

Shahiduzzaman, M., \& Alam, K. (2017). Trade-off between CO2 emissions and income: is there any evidence of an Environmental Kuznets Curve in Australia? Applied Economics Quarterly, 63(2), 211-231.

Sim, N., \& Zhou, H. (2015). Oil prices, US stock return, and the dependence between their quantiles. Journal of Banking \& Finance, 55, 1-8.

Sinha, A., \& Shahbaz, M. (2018). Estimation of Environmental Kuznets Curve for CO2 emission: Role of renewable energy generation in India. Renewable Energy, 119, 703-711.

Stern, D. I., Common, M. S., \& Barbier, E. B. (1996). Economic growth and environmental degradation: the environmental Kuznets curve and sustainable development. World Development, 24(7), 1151-1160.

Strezov, V., Evans, A., \& Evans, T. J. (2017). Assessment of the economic, social and environmental dimensions of the indicators for sustainable development. Sustainable Development, 25(3), 242-253.

Suri, V., \& Chapman, D. (1998). Economic growth, trade and energy: implications for the environmental Kuznets curve. Ecological Economics, 25(2), 195-208.

Uddin, G. A., Salahuddin, M., Alam, K., \& Gow, J. (2017). Ecological footprint and real income: panel data evidence from the 27 highest emitting countries. Ecological Indicators, 77, 166-175.

Yusuf, A. M., Abubakar, A. B., \& Mamman, S. O. (2020). Relationship between greenhouse gas emission, energy consumption, and economic growth: evidence from some selected oil-producing African countries. Environmental Science and Pollution Research, 1-9.

Zaman, K., Abdullah, I., \& Ali, M. (2017). Decomposing the linkages between energy consumption, air pollution, climate change, and natural resource depletion in Pakistan. Environmental Progress \& Sustainable Energy, 36(2), 638-648.

Zhang, B., Wang, B., \& Wang, Z. (2017). Role of renewable energy and non-renewable energy consumption on EKC: evidence from Pakistan. Journal of Cleaner Production, 156, 855-864.

Zoundi, Z. (2017). CO2 emissions, renewable energy and the Environmental Kuznets Curve, a panel cointegration approach. Renewable and Sustainable Energy Reviews, 72, 1067-1075.

Zuo, X., Hua, H., Dong, Z., \& Hao, C. (2017). Environmental performance index at the provincial level for China 2006-2011. Ecological Indicators, 75, 48-56. 